\title{
The Effects of Aquilaria Malaccensis Leaves Aqueous Extract on The Sperm of Sprague Dawley Rats Towards Early Embryogenesis
}

Faridah Ismail ${ }^{1}$, Azantee Yazmie Abdul Wahab ${ }^{2}$, Muhammad Lokman Md Isa ${ }^{3}$, Redzuan Nul Hakim Abdul Razak ${ }^{3}$, Raja Arif Shah Raja Ismail ${ }^{2}$

${ }^{1}$ Department of Basic Medical Sciences, Kulliyyah of Medicine, International Islamic University Malaysia

${ }^{2}$ IIUM Fertility Centre, International Islamic University Malaysia

${ }^{3}$ Department of Basic Medical Sciences, Kulliyyah of Nursing, International Islamic University Malaysia

Presenter: Faridah Ismail

Introduction: Oxidative stress induced by excessive and unopposed levels of reactive oxygen species in male reproductive system results in impaired sperm quality, fertilization capacity and poor embryo development. Our goal is to assess the potential effects of Aquilaria malaccensis (AM) leaves, a plant with strong antioxidant property on early embryo development in vitro and embryo quality following fertilization with cyclophosphamide (CP) exposed rat sperm. Materials and Methods: Forty eight male Sprague Dawley rats were allocated into eight groups of six rats $(\mathrm{n}=6)$ : control, CP only $(200 \mathrm{mg} / \mathrm{kg}), \mathrm{AM}$ only $(100 \mathrm{mg} / \mathrm{kg}, 300$ $\mathrm{mg} / \mathrm{kg}$ and $500 \mathrm{mg} / \mathrm{kg})$ and $C P+A M(100 \mathrm{mg} / \mathrm{kg}, 300 \mathrm{mg} / \mathrm{kg}$ and $500 \mathrm{mg} / \mathrm{kg})$. Animals were sacrificed after 63 days of treatment and sperm from caudal epididymis were taken for in vitro fertilization (IVF) with oocytes from untreated female. Fertilization, embryo division and embryo morphology were examined after 24 hours post fertilization and compared between groups. Statistical evaluations were performed using Chi-Square test and Fisher's exact test and pvalue < 0.05 was considered significant. Results: Co-administration of $A M$ leaves extract at dose $100 \mathrm{mg} / \mathrm{kg} /$ day to CP-treated group has significantly increased $(\mathrm{p}<$ 0.05 ) the fertilization rate, early cleavage rate and embryo quality compared to $\mathrm{CP}$ only treated group. Conclusion: Overall, the present results indicate the potential of $A M$ leaves extract supplementation to improve the fertility and early embryo development in male rat exposed to CP by inhibiting the oxidative processes and scavenging free radicals. 